\title{
Chamber simulation of photooxidation of dimethyl sulfide and isoprene in the presence of $\mathrm{NO}_{\mathrm{x}}$
}

\author{
T. Chen and M. Jang \\ Department of Environmental Engineering Sciences, P.O. Box 116450, University of Florida, Gainesville, FL, 32611, USA
}

Correspondence to: M. Jang (mjang@ufl.edu)

Received: 17 February 2012 - Published in Atmos. Chem. Phys. Discuss.: 8 June 2012

Revised: 19 October 2012 - Accepted: 22 October 2012 - Published: 6 November 2012

\begin{abstract}
To improve the model prediction for the formation of $\mathrm{H}_{2} \mathrm{SO}_{4}$ and methanesulfonic acid (MSA), aerosol-phase reactions of gaseous dimethyl sulfide (DMS) oxidation products [e.g., dimethyl sulfoxide (DMSO)] in aerosol have been included in the DMS kinetic model with the recently reported gas-phase reactions and their rate constants. To determine the rate constants of aerosol-phase reactions of both DMSO and its major gaseous products [e.g., dimethyl sulfone $\left(\mathrm{DMSO}_{2}\right)$ and methanesulfinic acid (MSIA)], DMSO was photooxidized in the presence of $\mathrm{NO}_{\mathrm{x}}$ using a $2 \mathrm{~m}^{3}$ Teflon film chamber. The rate constants tested in the DMSO kinetic mechanisms were then incorporated into the DMS photooxidation mechanism. The model simulation using the newly constructed DMS oxidation mechanims was compared to chamber data obtained from the phototoxiation of DMS in the presence of $\mathrm{NO}_{\mathrm{x}}$. Within 120-min simulation, the predicted concentrations of MSA increase by $200-400 \%$ and those of $\mathrm{H}_{2} \mathrm{SO}_{4}$, by $50-200 \%$ due to aerosol-phase chemistry. This was well substantiated with experimental data. To study the effect of coexisting volatile organic compounds, the photooxidation of DMS in the presence of isoprene and $\mathrm{NO}_{\mathrm{x}}$ has been simulated using the newly constructed DMS kinetic model integrated with the Master Chemical Mechanism (MCM) for isoprene oxidation, and compared to chamber data. With the high concentrations of DMS (250 ppb) and isoprene (560$2248 \mathrm{ppb}$ ), both the model simulation and experimental data showed an increase in the yields of MSA and $\mathrm{H}_{2} \mathrm{SO}_{4}$ as the isoprene concentration increased.
\end{abstract}

\section{Introduction}

Dimethyl sulfide (DMS) is a major reduced sulfur compound of marine origin. The major aerosol phase products of DMS are methanesulfonic acid (MSA) and sulfuric acid $\left(\mathrm{H}_{2} \mathrm{SO}_{4}\right)$ (Bardouki et al., 2003; Barone et al., 1995; Gaston et al., 2010; Lukacs et al., 2009), both of which are postulated to have significant effects on the earth's radiation budget (Charlson et al., 1987). The DMS photooxidation mechanism is an important factor for understanding the role DMS plays in the earth's sulfur cycle and climate system, so it has been studied by many researchers (Yin et al., 1990a; Turnipseed and Ravishankara, 1993; Urbanski and Wine, 1999; Barnes et al., 2006).

Despite all the efforts exerted to understanding atmospheric DMS chemistry, a large discrepancy still exists between the ambient measurements of DMS products and the simulation results for compounds such as DMSO (dimethyl sulfoxide) (Chen et al., 2000), $\mathrm{H}_{2} \mathrm{SO}_{4}$ and MSA (Lucas and Prinn, 2002). The poor predictive capability of the kinetic model for the formation of DMS products was caused by uncertainties in the rate constants of DMS reactions in the gas phase, the lack of aerosol phase reactions of the DMS products, and missing information regarding the impact of volatile organic compounds (VOC) on the DMS photooxidation through both the gas and the particle phases.

In the presence of UV light, DMS oxidation is initiated by $\mathrm{OH}$ - radical reactions through both the hydrogen $(\mathrm{H})$ abstraction reaction and the addition reaction (Atkinson et al., 1989). It is known that DMS also reacts with $\mathrm{O}\left({ }^{3} \mathrm{P}\right), \mathrm{NO}_{3}$ (Atkinson et al., 1989) and $\mathrm{NO}_{2}$ (Balla and Heicklen, 1984). Tables S1-S3 of the Supplement summarize the reaction mechanisms and their rate constants of the DMS oxidation used in this study. Tables S1-S3 have been constructed mainly based on the study by Yin et al. (1990a). In this study, some of reaction rate constants have been updated using recently reported values and new reaction mechanisms 
(e.g., the DMS reaction with DMS origin radical species) have also been included in this study. For example, the rate constant $\left(\mathrm{s}^{-1}\right.$ molecules $\left.{ }^{-1} \mathrm{~cm}^{3}\right)$ for the $\mathrm{OH}$ radical abstraction reaction of DMS (No. 59) was suggested to be $1.13 \times 10^{-11} \exp (-254 / T)$ by Atkinson et al. (1997); the rate constant for the $\mathrm{OH}$ radical addition reaction to DMSO (No. 2) was updated to $6.1 \times 10^{-12} \exp (800 / T)$ (Sander et al., 2006). Two other initial reactions of DMSO oxidation (No. 1 and 3) were newly added (Sander et al., 2006). The change of the reaction rate constants may influence both the prediction of the DMS decay and its product distribution.

Although the prediction of MSA and $\mathrm{H}_{2} \mathrm{SO}_{4}$ is affected by different gas mechanisms employed in the model (Karl et al., 2007), the large discrepancy in the concentrations of MSA and $\mathrm{H}_{2} \mathrm{SO}_{4}$ between observation and model results cannot be explained solely by the uncertainties in gas phase chemistry. No expression of aerosol-phase reactions in the DMS mechanism is another reason why MSA and $\mathrm{H}_{2} \mathrm{SO}_{4}$ have been underpredicted using the existing gas phase kinetic model (Yin et al., 1990a). Recent field studies indicate that the aerosolphase reactions of DMS products significantly contribute to the formation of MSA in the aerosol. For example, in a field study in the equatorial Pacific, Davis et al. (1999) indicated that the production of MSA through gas to particle partitioning account for only $1 \%$ of the observed aerosol phase MSA. Similarly, through an eastern Mediterranean campaign, Mihalopoulos et al. (2007) suggested that at least $80 \%$ of the production of aerosol phase MSA may be due to aerosolphase reactions of DMS photooxidation products (possibly DMSO). Campolongo et al. (1999) have found a better match between the measured MSA and the model prediction when the aqueous phase reactions of the DMS oxidation products were considered. Bardouki et al. (2002) confirmed that the liquid phase reactions of DMSO and methanesulfinic acid (MSIA) with $\mathrm{OH}$ radicals produce MSA with high yields. To better predict the atmospheric fate of DMS, the development of an advanced kinetic model incorporating aqueous phase chemistry is needed.

The lack of consideration of the impact of VOC on the DMS photooxidation also affects the model's predictive ability for DMS oxidation products in ambient studies. In a recent indoor chamber study, Chen and Jang (2012) discovered that the MSA production from DMS photooxidation is affected by the presence of isoprene. However, no further kinetic studies of the impact of coexisting VOCs on DMS chemistry has been conducted.

In this study, a new DMS kinetic model was developed by including not only the most recently reported reactions and their rate constants (Barnes et al., 2006; Sander et al., 2006), but also the aerosol-phase reactions of DMS gaseous products in aerosol phase. To determine the rate constants of the aerosol-phase reactions of both DMSO and its major gaseous products dimethyl sulfone $\left(\mathrm{DMSO}_{2}\right)$ and methanesulfinic acid (MSIA), the model was first simulated on the basis of the experimental data for the DMSO photooxidation in the presence of $\mathrm{NO}_{\mathrm{x}}$ using a $2 \mathrm{~m}^{3}$ indoor chamber. The resulting DMSO reactions were incorporated into the kinetic mechanisms for simulating the DMS.

To study the influence of atmospheric VOCs on DMS oxidation, the new DMS photooxidation mechanisms was were coupled with the isoprene photooxidation kinetic model from included in the Master Chemical Mechanism (MCM) v3.2 (Jenkin et al., 1997; Saunders et al., 2003), which is available, via the website at: $\mathrm{http}: / / \mathrm{mcm}$.leeds.ac.uk/MCM/. The resulting model was also simulated for the chamber data. Isoprene has been chosen as a representative of the biogenic VOC here mainly because it has a large emission (440$660 \mathrm{TgC} \mathrm{yr}^{-1}$ ) (Guenther et al., 2006) and it is also known to be an important VOC from the ocean (Palmer, 2005). In addition to the high flux of isoprene, the secondary organic aerosol (SOA) yields from isoprene are sensitive to the aerosol acidity from $\mathrm{H}_{2} \mathrm{SO}_{4}$ (Czoschke et al., 2003; Edney et al., 2005) as well as from the DMS photooxidation products (Chen and Jang, 2012). It is therefore interesting to study the impact of isoprene on the formation of DMS photooxidation products.

Field studies show that the mean isoprene concentration in the remote oceans and coastal watersheds can be as high as $300 \mathrm{ppt}$, varying with time of day, season and location (Shaw et al., 2010), and the coastal concentration of DMS is usually 50-200 ppt (Ramanathan et al., 2001). In our study the mixing ratio of isoprene to DMS was controlled between 2 and 8 to mimic the ambient air in coastal watersheds. The $\mathrm{NO}_{\mathrm{x}}$ concentration we use is in the range of $15-200 \mathrm{ppb}$, representing areas of different levels of anthropogenic air pollution. Although halogen compounds are known to react fast with DMS (Barnes et al., 2006), in the coastal areas with human activities, $\mathrm{OH}$ radical reactions with DMS and its products will be dominant. In this study, we mainly focus on the $\mathrm{OH}$ radical reaction with DMS.

\section{Experimental section}

\subsection{Indoor Teflon-film chamber experiments of photooxidation of DMSO and DMS}

\subsubsection{Experiment procedures}

Since the DMSO oxidation mechanism is an important subset of DMS oxidation mechanism, five $\mathrm{DMSO} / \mathrm{NO}_{\mathrm{x}}$ experiments were conducted to evaluate the DMSO submodel. The experiments were conducted using a $2 \mathrm{~m}^{3}$ Teflon indoor chamber equipped with 16 UV lamps (Solarc Systems Inc., FS40T12/UVB) covering the wavelengths between 280 and $900 \mathrm{~nm}$. The chamber was flushed using air from clean air generators (Aadco Model 737, Rockville, MD; Whatman Model 75-52, Haverhill, MA). Prior to each photoirradiation experiment, the chamber background air was analyzed to determine the carryover from the previous experiments (e.g., 
Table 1. Chamber experiments of the photooxidation of DMS and DMSO in the presence of $\mathrm{NO}_{\mathrm{x}}$.

\begin{tabular}{cccccc}
\hline Exp & Temp, ${ }^{\circ} \mathrm{C}^{*}$ & $\mathrm{RH}^{\mathrm{a}}{ }^{\mathrm{a}}$ & Initial sulfur conc., ppb & Initial NO conc., ppb & Initial NO $_{2}$ conc., ppb \\
\hline DMSO-1 & 22 & 24 & 291.3 & 47.9 & 1.1 \\
DMSO-2 & 22 & 26 & 306.5 & 199.1 & 0 \\
DMSO-3 & 21 & 23 & 99.1 & 32.0 & 1.0 \\
DMSO-4 & 24 & 24 & 170.0 & 79.7 & 5.3 \\
DMSO-5 & 26 & 27 & 75.7 & 32.0 & 1.0 \\
DMS-1 & 24 & 28 & 714.0 & 102.7 & 1.0 \\
DMS-2 & 26 & 28 & 210.0 & 116.8 & 3.1 \\
DMS-3 & 25 & 28 & 146.0 & 25.4 & 1.0 \\
DMS-4 & 27 & 40 & 134.0 & 61.9 & 0.5 \\
DMS-5 & 25 & 60 & 161.0 & 0 \\
\hline
\end{tabular}

* Accuracy of RH: $\pm 2 \%$; accuracy of temperature: $\pm 0.5^{\circ} \mathrm{C}$.

Table 2. Chamber experimental conditions for isoprene photooxidation with and without DMS.

\begin{tabular}{|c|c|c|c|c|c|c|}
\hline $\operatorname{Exp}$ & Temp, ${ }^{\circ} \mathrm{C}^{\mathrm{a}}$ & $\mathrm{RH} \%^{\mathrm{a}}$ & Initial DMS conc., ppb & Initial isoprene conc., ppb & Initial NO conc., ppb & Initial $\mathrm{NO}_{2}$ conc., $\mathrm{ppb}$ \\
\hline iso-1 & 24.5 & 30 & 0 & 644 & 66.7 & 10.2 \\
\hline iso-2 & 25.0 & 32 & 0 & 600 & 20.0 & 6.7 \\
\hline iso-DMS-1 & 23.5 & 28 & 243 & 560 & 77.3 & 7.5 \\
\hline iso-DMS-2 & 23.2 & 30 & 265 & 1360 & 79.9 & 4.6 \\
\hline iso-DMS-3 & 23.0 & 30 & 276 & 2248 & 62.0 & 3.9 \\
\hline iso-DMS-4 & 22.0 & 10 & 31 & 210 & 39.0 & 1.3 \\
\hline iso-DMS-5 & 23.1 & 30 & $20^{\mathrm{b}}$ & $40^{\mathrm{b}}$ & 15.6 & 0 \\
\hline
\end{tabular}

a Accuracy of RH: $\pm 2 \%$; accuracy of temperature: $\pm 0.5^{\circ} \mathrm{C}$.

b Initial DMS and isoprene concentrations in iso-DMS-5 were estimated based on the amount of injected chemicals due to the instrumental detection limit.

DMSO and $\mathrm{DMSO}_{2}$ ). The chamber humidity was controlled by introducing humidified air streams into the chamber until the relative humidity $(\mathrm{RH})$ in the chamber reached the desired value. The RH was measured at the beginning of experiment and corrected for temperature change (up to $5 \mathrm{~K}$ ) over the course of the experiment. After flushing the chamber with the clean air, the background aerosol concentration was below $0.20 \mu \mathrm{g} \mathrm{m}^{-3}$ and the concentrations of the DMSO and $\mathrm{DMSO}_{2}$ were below $2 \%$ of the initial sulfur concentrations (Tables 1, 2 and 3) of each chamber experiment. DMSO was added to the chamber by passing clean air through a $\mathrm{T}$ union where DMSO (99.6\%, Sigma-Aldrich) was injected using a syringe and gently heated using a heat gun. $\mathrm{CCl}_{4}$ was injected for chamber dilution. $\mathrm{NO}_{\mathrm{x}}(99.5 \%$ nitric oxide, Airgas) was injected into the chamber by inserting a syringe through the injection ports. When the initial concentration of $\mathrm{NO}_{\mathrm{x}}$ was stable, UV lamps were turned on.

The procedures of the $\mathrm{DMS} / \mathrm{NO}_{\mathrm{x}}$ experiments were same as those of the DMSO/NO $\mathrm{NO}_{\mathrm{x}}$ experiments except that DMS ( $99.7 \%$, Aldrich) was injected into the chamber using a syringe without heating. The detailed experimental conditions for DMSO and DMS photooxidation reactions are summarized in Table 1.

\subsubsection{Instrumentation and sample analysis}

The concentrations of DMS, $\mathrm{SO}_{2}, \mathrm{NO}_{\mathrm{x}}$ and $\mathrm{O}_{3}$ in the chamber were measured using an HP 5890 gas chromatographyflame ionization detector (GC-FID), a fluorescence TRS analyzer (Teledyne Model 102E), a chemiluminescence $\mathrm{NO} / \mathrm{NO}_{\mathrm{x}}$ analyzer (Teledyne Model 200E) and a photometric ozone analyzer (Teledyne model 400E). Particle concentrations were measured using a scanning mobility particle sizer (SMPS, TSI, Model 3080, MN) combined with a condensation nuclei counter (CNC, TSI, Model 3025A). A particleinto-liquid sampler (Applikon, ADI 2081) coupled with an ion chromatography (Metrohm, 761 Compact IC) (PILS-IC) was used to measure the major aerosol products (e.g., MSA and $\mathrm{H}_{2} \mathrm{SO}_{4}$ ) produced from DMS photooxidation. The detection limit of PILS-IC is $0.1 \mu \mathrm{g} \mathrm{m}^{-3}$ and the associated error is $\pm 10 \%$.

DMSO and $\mathrm{DMSO}_{2}$ were collected using a liquid $\mathrm{N}_{2}$ $\left(\sim-195^{\circ} \mathrm{C}\right)$ trap for $8-10 \mathrm{~min}$ at a flow rate of $3 \mathrm{~L} \mathrm{~min}^{-1}$. $3 \mathrm{ml}$ of acetonitrile (optima grade) with deuterated DMSO ( $d_{6}$-DMSO, used as an internal standard) were then added to the trap, which was subsequently capped and immersed into hot water $\left(\sim 60^{\circ} \mathrm{C}\right)$ for $10 \mathrm{~min}$. The liquid in the trap was then transferred to a small vial for chromatography ion trap mass spectrometer (GC-ITMS, Varian model CP-3800 GC, Saturn model 2200 MS) analysis. The analysis of DMSO and 
Table 3. Model simulation of the yields of MSA and $\mathrm{H}_{2} \mathrm{SO}_{4}$ and the integrating reaction rates (IRR) of the formation of $\mathrm{MSA}$ and $\mathrm{H}_{2} \mathrm{SO}_{4}$ in the presence of different amount of isoprene ${ }^{\mathrm{a}}$.

\begin{tabular}{|c|c|c|c|c|c|c|c|c|c|}
\hline \multirow{3}{*}{ Exp } & \multirow{3}{*}{$\begin{array}{c}\text { Isoprene } \\
\text { ppb }\end{array}$} & \multirow{3}{*}{$\begin{array}{l}\text { Sim. time } \\
\text { min }\end{array}$} & \multirow{3}{*}{$\begin{array}{c}\Delta \mathrm{DMS}, \\
\mathrm{ppb}\end{array}$} & & & \multicolumn{4}{|c|}{ IRR normalized by $\Delta \mathrm{DMS}^{\mathrm{b}}$} \\
\hline & & & & \multicolumn{2}{|c|}{ Molar yield $^{\mathrm{d}}$} & \multicolumn{2}{|c|}{ MSA } & \multicolumn{2}{|c|}{$\mathrm{H}_{2} \mathrm{SO}_{4}$} \\
\hline & & & & MSA & $\mathrm{H}_{2} \mathrm{SO}_{4}$ & gas pathway ${ }^{\mathrm{e}}$ & aerosol pathway ${ }^{\mathrm{f}}$ & gas pathwaye & aerosol pathway ${ }^{\mathrm{f}}$ \\
\hline iso-DMS-1 & 560 & 44 & 6.4 & $10.3 \%(11.3 \%)$ & $1.0 \%(2.7 \%)$ & 0.097 & 0 & 0.009 & 0 \\
\hline iso-DMS-2 & 1360 & 50 & 5.9 & $12.2 \%(13.7 \%)$ & $1.2 \%(2.8 \%)$ & 0.105 & 0.002 & 0.012 & 0 \\
\hline iso-DMS-3 & 2248 & 163 & 6.0 & $13.1 \%(29.1 \%)$ & $2.0 \%(3.3 \%)$ & 0.115 & 0.005 & 0.022 & 0 \\
\hline
\end{tabular}

a All the reported results (except those in brackets) in this table were based on the model simulation. The experimental yield data are in the brackets. The MSA yields in this table were calculated using the data from Fig. 4 with corrections for DMS wall loss and chamber dilution. Note that the DMS decay in Fig. 4 contains the decay due to photooxidation, wall loss and chamber dilution.

${ }^{b}$ Refer to 3.3.1 for the description of IRR.

c The simulation time was set so that the consumed DMS was fixed at around $6 \mathrm{ppb}$ for fair comparison among different systems.

${ }^{d}$ Molar yield is defined as the amount of MSA ( $\mathrm{or}_{2} \mathrm{SO}_{4}$ ) formed divided by the amount (around $6 \mathrm{ppb}$ ) of DMS consumed.

e The IRR for Reaction (R48) and (R54) in Table S1 and Reaction (R132) in Table S2 were added up for MSA formation while the IRR for Reaction (R170) and (R171) in Table $\mathrm{S} 3$ were added up for $\mathrm{H}_{2} \mathrm{SO}_{4}$ formation.

${ }^{f}$ The IRR for MSA formation was based on Reaction (R8) in Sect. 3.1.2 and that for $\mathrm{H}_{2} \mathrm{SO}_{4}$ formation was from Reaction (R9) in the same section.

$\mathrm{DMSO}_{2}$ in solution using GC-ITMS has been presented by Takeuchi et al. (2010). The GC temperature profile in our study is $70^{\circ} \mathrm{C}$ for $1 \mathrm{~min}$; ramp to $90^{\circ} \mathrm{C}$ at $5^{\circ} \mathrm{C} \mathrm{min}-1$; ramp to $280^{\circ} \mathrm{C}$ at $20^{\circ} \mathrm{C} \mathrm{min}^{-1}$ and hold for $8 \mathrm{~min}$. Figure $\mathrm{S} 1$ in the Supplement summarizes the retention time and mass spectra of DMSO, $\mathrm{DMSO}_{2}$ and $d_{6}$-DMSO for the GC/MS analysis. The concentrations of DMSO and $\mathrm{DMSO}_{2}$ were determined by the calibration curve produced using authentic standards with an internal standard ( $d_{6}$-DMSO). The associated error with the measured concentrations of DMSO and $\mathrm{DMSO}_{2}$ is $\pm 20 \%$.

\subsection{Indoor Teflon-film chamber experiments of DMS photooxidation in the presence of isoprene}

In addition to the monitoring of ozone, $\mathrm{NO}_{\mathrm{x}}$, and DMS, major isoprene photooxidation products [methacrolein (P1), methyl vinyl ketone (P2), glyoxal (P3), and methylglyoxal (P4)] were sampled every $30 \mathrm{~min}$ (10 min sampling) for $2.5 \mathrm{~h}$ (5 samples in total) with a flow rate of $1.0 \mathrm{~L} \mathrm{~min}^{-1}$ using an impinger that contained $12 \mathrm{~mL}$ of acetonitrile with bornyl acetate (internal standard). Further descriptions of derivatization methods for carbonyls (O- $(2,3,4,5,6-$ Pentafluorobenzyl)-hydroxylamine hydrochloride, PFBHA) can be found elsewhere (Im et al., 2011).

All the impinger samples were analyzed by the GC-ITMS with the temperature program as follows: $80^{\circ} \mathrm{C}$ for $1 \mathrm{~min}$; ramp to 100 at $5^{\circ} \mathrm{C} \mathrm{min}^{-1}$; hold for $3 \mathrm{~min}$; ramp to $280^{\circ} \mathrm{C}$ at $10{ }^{\circ} \mathrm{C} \mathrm{min}^{-1}$ and hold for $8 \mathrm{~min}$. The description of detailed analytical procedures for the quantification of products can be found in the previous study (Im et al., 2011). The errors associated with the GC/MS analyses for isoprene products are $\pm 30 \%$.

\section{Results and discussion}

\subsection{Kinetic model}

\subsubsection{Reaction mechanisms of DMS}

DMS photooxidation in the presence of $\mathrm{NO}_{\mathrm{x}}$ in the indoor chamber was simulated using explicit kinetic mechanisms integrated with the Morpho kinetic solver (Jeffries, 1998). Tables S1-3 (in the Supplement) summarize the kinetic mechanisms related to DMS oxidation along with their reaction rate constants, which were collected from the recent literature. The reaction rate constants of the oxidation for the non-sulfur compounds (e.g., formaldehyde, methanol, and methane, etc) are obtained from the MCM mechanisms (Jenkin et al., 1997; Saunders et al., 2003).

\subsubsection{Formation of MSA and $\mathrm{H}_{2} \mathrm{SO}_{4}$ through aerosol-phase reactions of gaseous DMS oxidation products}

For the prediction of DMS oxidation products in aerosol, most explicit models expressing DMS photooxidation (e.g., Yin et al., 1990a) in the gas phase lack the description of aerosol-phase chemistry of DMS oxidation products. In the model of this study, we assumed that DMSO produces MSIA, which consequently forms MSA in the aerosol phase (Bardouki et al., 2002), and $\mathrm{DMSO}_{2}$ produces $\mathrm{H}_{2} \mathrm{SO}_{4}$ through aerosol-phase reactions (Koga and Tanaka, 1993). The aerosol-phase reaction of $\mathrm{SO}_{2}$ in $\mathrm{H}_{2} \mathrm{SO}_{4}$ aerosol has been found insignificant (Rattigan et al., 2000), so it is not included in the model.

The nucleation of gaseous MSA and $\mathrm{H}_{2} \mathrm{SO}_{4}$ originating from DMS photooxidation produces an aerosol mass suitable for partitioning of organic compounds. In our model, both MSA and $\mathrm{H}_{2} \mathrm{SO}_{4}$ are predominantly present in the aerosol 
phase and their total mass is expressed as "Aerosol" in this mechanism.

$$
[\text { Aerosol }]=\left[\mathrm{H}_{2} \mathrm{SO}_{4}\right]+[\mathrm{MSA}]
$$

where squared brackets denote concentration. The DMSO present in the gas phase is denoted as $\mathrm{CH}_{3}-\mathrm{S}(\mathrm{O}) \mathrm{CH}_{3}(g)$. In the same way, the gas phase MSIA is denoted as $\mathrm{CH}_{3}-\mathrm{S}(\mathrm{O}) \mathrm{OH}(\mathrm{g})$ and the gas phase $\mathrm{DMSO}_{2}$ is denoted as $\mathrm{CH}_{3}(\mathrm{O}) \mathrm{S}(\mathrm{O}) \mathrm{CH}_{3}(\mathrm{~g})$. The particle phase, DMSO, MSIA, and $\mathrm{DMSO}_{2}$ are described as $\mathrm{CH}_{3}-\mathrm{S}(\mathrm{O}) \mathrm{CH}_{3}(p)$, $\mathrm{CH}_{3}-\mathrm{S}(\mathrm{O}) \mathrm{OH}(p)$ and $\mathrm{CH}_{3}(\mathrm{O}) \mathrm{S}(\mathrm{O}) \mathrm{CH}_{3}(p)$, respectively.

In order to include aerosol-phase reactions of gaseous DMS oxidation products, the rates of absorption $\left({ }^{i} k_{\mathrm{abs}}\right.$, $\mathrm{cm}^{3}$ molecules $\left.{ }^{-1} \mathrm{~s}^{-1}\right)$ and desorption $\left({ }^{i} k_{\mathrm{des}}, \mathrm{s}^{-1}\right)$ of the gaseous organic compounds (Kamens et al., 1999), have been added to the new model. The ${ }^{i} k_{\text {abs }}{ }^{i} k_{\text {des }}$ value is equal to the equilibrium constant, ${ }^{i} K_{p}$, for the gas-particle equilibrium of a given partitioning compound.

${ }^{i} K_{p}={ }^{i} k_{\mathrm{abs}} /{ }^{i} k_{\mathrm{des}}$

${ }^{i} K_{p}$ is estimated using the following equation (Pankow, 1994),

${ }^{i} K_{p}=7.501 R T /\left(10^{9} M W^{i} \gamma^{i} p_{L}\right)$

where $M W$ is the average molecular weight of the aerosol medium (e.g., $45 \mathrm{~g} \mathrm{~mol}^{-1}$ at relative humidity $=30 \%$ ), ${ }^{i} p_{L}$ is the vapor pressure of compound $i$, and ${ }^{i} \gamma$ is the activity coefficient of compound $i$ at a given medium. The ${ }^{i} \gamma$ values for the compounds (DMSO, $\mathrm{DMSO}_{2}$ and MSIA) of interest in this study are unknown. For DMSO, the ${ }^{i} \gamma$ value is estimated from the relationship between ${ }^{i} K_{p}$ and Henry's law constant $(H)$.

$\frac{{ }^{i} K_{p}}{H}=\frac{7.501 \times R T V}{10^{9} M W}$

where $V$ is molar volume of the medium. The calculated ${ }^{i} K_{p}$ value of DMSO is $1.3 \times 10^{-5} \mathrm{\mu g} \mathrm{m}^{-3}$ and the estimated ${ }^{i} \gamma$ is 0.023 at $T=298 \mathrm{~K}$. Then the ${ }^{i} \gamma$ for DMSO was applied to the estimation of ${ }^{i} K_{p}$ values of $\mathrm{DMSO}_{2}$ and MSIA using Eq. (3) although the ${ }^{i} \gamma$ value of DMSO might be different from those of $\mathrm{DMSO}_{2}$ and MSIA.

The detailed description of the determination of ${ }^{i} k_{\mathrm{abs}}$ and ${ }^{i} k_{\text {des }}$ is shown in the Supplement. In brief, based on the analysis of the characterization times $(\tau)$, the equilibrium process $\left(\tau_{\mathrm{eq}}=\sim 10^{1} \mathrm{~s}\right)$ governed by the absorption and the desorption processes of the compound between the gas and the particle is much faster than the reaction in the gas phase $\left(\tau_{\text {gas }}=\sim 10^{5} \mathrm{~s}\right)$. Hence, the determination of the absolute values of ${ }^{i} k_{\text {abs }}$ and ${ }^{i} k_{\text {des }}$ becomes less important as long as the $\tau$ values of both absorption and desorption are much shorter (within computer process time) than that of gas-phase reaction. In this study, the $\tau$ value of the absorption process is set to $\sim 10^{-4} \mathrm{~s}$ and is applied to the estimation of both ${ }^{i} k_{\mathrm{abs}}$ and ${ }^{i} k_{\text {des }}$. The $\tau$ of the desorption process of all three compounds are in the order of $\sim 10^{-8} \mathrm{~s}$.

The partitioning processes of DMSO, MSIA and $\mathrm{DMSO}_{2}$ are described as follows.

$$
\begin{aligned}
& \mathrm{CH}_{3}-\mathrm{S}(\mathrm{O}) \mathrm{CH}_{3}(g)+\text { Aerosol } \rightarrow \mathrm{CH}_{3}-\mathrm{S}(\mathrm{O}) \mathrm{CH}_{3}(p)+\text { Aerosol } \\
& { }^{i} k_{\mathrm{abs}}=1.4 \times 10^{-6} \\
& \mathrm{CH}_{3}-\mathrm{S}(\mathrm{O}) \mathrm{CH}_{3}(p) \rightarrow \mathrm{CH}_{3}-\mathrm{S}(\mathrm{O}) \mathrm{CH}_{3}(g) \\
& { }^{i} k_{\text {des }}=3.8 \times 10^{8} \\
& \mathrm{CH}_{3}-\mathrm{S}(\mathrm{O}) \mathrm{OH}(g)+\text { Aerosol } \rightarrow \mathrm{CH}_{3}-\mathrm{S}(\mathrm{O}) \mathrm{OH}(p)+\text { Aerosol } \\
& { }^{i} k_{\mathrm{abs}}=1.4 \times 10^{-6} \\
& \mathrm{CH}_{3}-\mathrm{S}(\mathrm{O}) \mathrm{OH}(p) \rightarrow \mathrm{CH}_{3}-\mathrm{S}(\mathrm{O}) \mathrm{OH}(g) \\
& { }^{i} k_{\mathrm{des}}=2.4 \times 10^{7} \\
& \mathrm{CH}_{3}(\mathrm{O}) \mathrm{S}(\mathrm{O}) \mathrm{CH}_{3}(g)+\text { Aerosol } \rightarrow \mathrm{CH}_{3}(\mathrm{O}) \mathrm{S}(\mathrm{O}) \mathrm{CH}_{3}(p)+\text { Aerosol }(\mathrm{R} 5) \\
& { }^{i} k_{\mathrm{abs}}=1.4 \times 10^{-6} \\
& \mathrm{CH}_{3}(\mathrm{O}) \mathrm{S}(\mathrm{O}) \mathrm{CH}_{3}(p) \rightarrow \mathrm{CH}_{3}(\mathrm{O}) \mathrm{S}(\mathrm{O}) \mathrm{CH}_{3}(g) \\
& { }^{i} k_{\mathrm{des}}=3.0 \times 10^{7}
\end{aligned}
$$

The reactions of aerosol-phase oxidation of DMSO, MSIA and $\mathrm{DMSO}_{2}$ in aerosol bulk phase are described as follows.

$$
\begin{aligned}
& \mathrm{CH}_{3}-\mathrm{S}(\mathrm{O}) \mathrm{CH}_{3}(p) \stackrel{h v}{\longrightarrow} \mathrm{CH}_{3}-\mathrm{S}(\mathrm{O}) \mathrm{OH}(p) \quad{ }^{i} k_{r}=4.8 \\
& \mathrm{CH}_{3}-\mathrm{S}(\mathrm{O}) \mathrm{OH}(p) \stackrel{h v}{\longrightarrow} \mathrm{CH}_{3}-\mathrm{SO}_{3} \mathrm{H} \quad{ }^{i} k_{r}=5.6 \\
& \mathrm{CH}_{3}(\mathrm{O}) \mathrm{S}(\mathrm{O}) \mathrm{CH}_{3}(p) \stackrel{h v}{\longrightarrow} \mathrm{CH}_{3}-\mathrm{SO}_{3} \mathrm{H}^{i} k_{r}=2.4 \times 10^{-3}
\end{aligned}
$$

where ${ }^{i} k_{r}\left(\mathrm{~s}^{-1}\right)$ is the rate constant for the aerosol-phase reaction of compound $i .{ }^{i} k_{r}$ values in Reactions (R7)-(R9) were empirically determined by fitting the predicted concentrations of MSA and $\mathrm{H}_{2} \mathrm{SO}_{4}$ to the experimentally observed concentrations. The major oxidants in the aerosol phase reaction of DMSO, $\mathrm{DMSO}_{2}$ and MSIA are $\mathrm{OH}$ radicals (Bardouki et al., 2002). The production of $\mathrm{OH}$ radicals in the particle phase is complex due to the photolysis of various $\mathrm{OH}$ radical precursors ( $\mathrm{ROOH}, \mathrm{H}_{2} \mathrm{O}_{2}$, and $\mathrm{HONO}$ ) and the partitioning of gas phase $\mathrm{OH}$ radicals to the particle. Hence the production of $\mathrm{OH}$ radicals in the aerosol depends on light intensity. In this study, we assume that the concentration of the particle phase $\mathrm{OH}$ radical is proportional to light intensity. The aerosol-phase chemistry is controlled by a single ${ }^{i} k_{r}$ value for each aerosol phase reaction in Reactions (R7)-(R9) since apparent reaction rate constants for multiphase reactions are obtained by fitting to the experimental data. Based on the analysis of the chemical flux using the integrated reaction rates in the model, the consumption of $\mathrm{OH}$ radicals through mechanisms Reactions (R7)-(R9) are less than $3 \%$ of the total $\mathrm{OH}$ radicals in the system suggesting that consumption of $\mathrm{OH}$ radicals through aerosol-phase reactions is insignificant. 


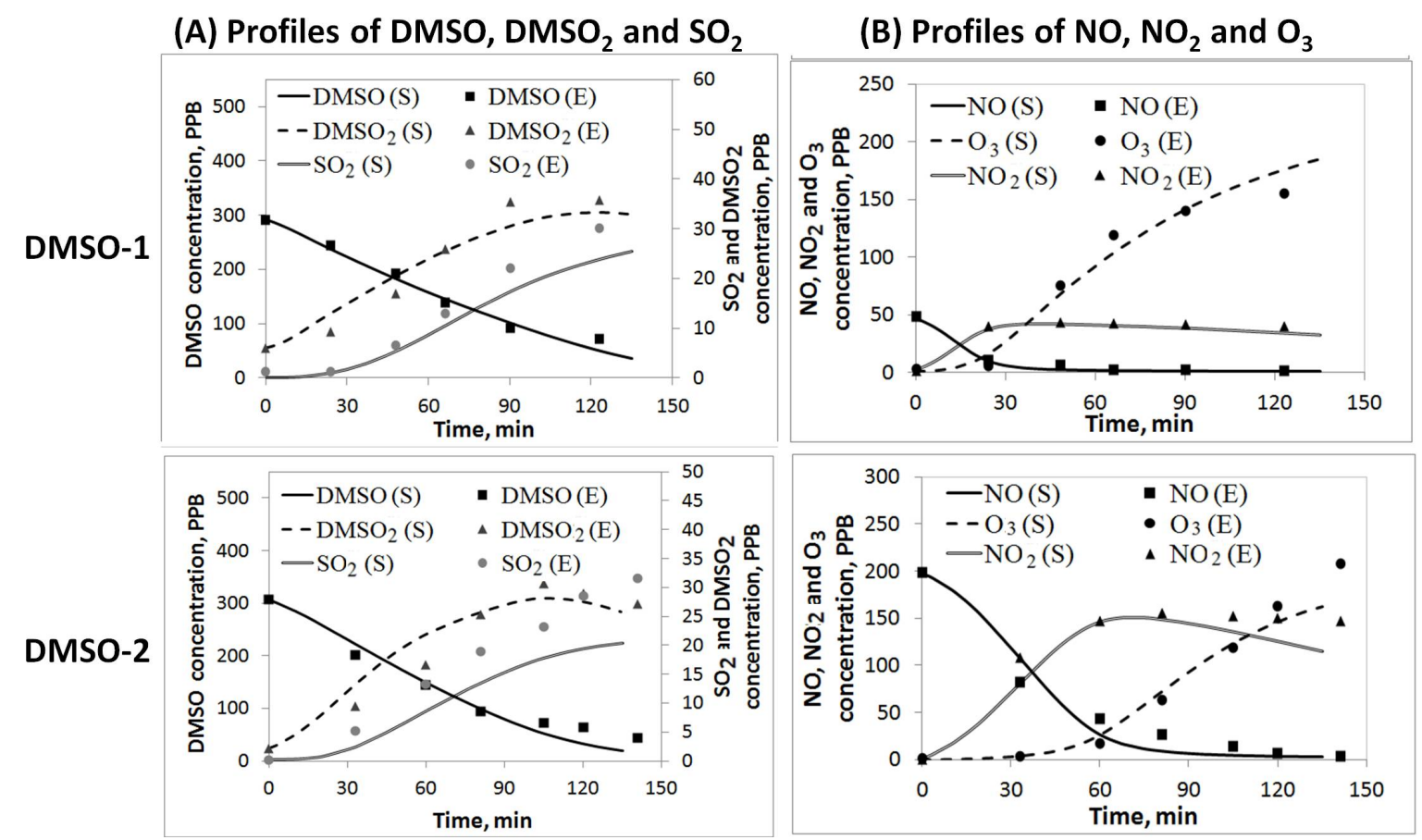

Fig. 1. Time profiles of DMSO, $\mathrm{DMSO}_{2}, \mathrm{SO}_{2}, \mathrm{NO}_{\mathrm{x}}$ and $\mathrm{O}_{3}$ for the photooxidation of DMSO in the presence of $\mathrm{NO}_{\mathrm{x}}$ (Exp DMSO-1 and DMSO-2 in Table 1). "E" denotes the experimentally observed concentrations of chemical species and "S" for those simulated using the kinetic model. The decay of DMSO was not corrected for the wall loss and chamber dilution.

\subsubsection{Isoprene oxidation mechanism}

The kinetic mechanisms of isoprene oxidation have been described using the MCM v3.2 (Jenkin et al., 1997; Saunders et al., 2003) and compared to the data from two experiments (Exp iso-1 and Exp iso-2 in Table 2) with different $\mathrm{NO}_{\mathrm{x}}$ concentrations. Welz et al. (2012) have recently measured the upper limit of the rate constants for the reaction of the stabilized Criegee radical $\left(\cdot \mathrm{CH}_{2} \mathrm{OO} \cdot\right)$ with a number of important atmospheric species, concluding that the reactions of . $\mathrm{CH}_{2} \mathrm{OO}$. with $\mathrm{NO}_{2}\left(7.0 \times 10^{-12} \mathrm{~cm}^{3}\right.$ molecules $\left.{ }^{-1} \mathrm{~s}^{-1}\right)$ and with $\mathrm{SO}_{2}\left(3.9 \times 10^{-11} \mathrm{~cm}^{3}\right.$ molecules $\left.{ }^{-1} \mathrm{~s}^{-1}\right)$ are much faster than the previous estimation. These new reaction rate constants were used to update the original constants in the MCM v3.2.

\subsection{DMS model simulation}

\subsubsection{Chamber characterization}

The photolysis rates of inorganic species and organic compounds were calculated using the chemical solver integrated with the wavelength-dependent absorption cross-sectional areas, quantum yields, and the chamber light intensity. The light spectrum inside the chamber was measured using a spectroradiometer (PS-300, Apogee). For the calibration of the light intensity inside the chamber, an $\mathrm{NO}_{2}$ photolysis experiment was separately conducted under the nitrogen gas
(99.95\%) environment. The detailed description of the light characterization procedure can be found in the previous study (Cao, 2008).

The chamber wall loss of oxidant gases such as $\mathrm{O}_{3}$ and $\mathrm{H}_{2} \mathrm{O}_{2}$ were determined through several dark chamber experiments. Their wall loss rates are estimated using a first order rate constant $\left(\mathrm{s}^{-1}\right): 2.5 \times 10^{-5}$ for $\mathrm{O}_{3}$ and $6.7 \times 10^{-4}$ for $\mathrm{H}_{2} \mathrm{O}_{2}$. The wall loss rate constants of DMS $\left(9 \times 10^{-6} \mathrm{~s}^{-1}\right)$, $\mathrm{SO}_{2}\left(2 \times 10^{-5} \mathrm{~s}^{-1}\right)$, DMSO $\left(6 \times 10^{-5} \mathrm{~s}^{-1}\right)$ and $\mathrm{DMSO}_{2}(7 \times$ $10^{-5} \mathrm{~s}^{-1}$ ) were also experimentally determined assuming the first order rate and applied to the reaction mechanisms (Table $\mathrm{S} 1-3$ ) to compare the simulated results to the experimental data. Table S4 summarizes the wall loss rate constants of the compounds of this study and those found in literature (Qi et al., 2007; Ballesteros et al., 2002; Yin et al., 1990a). For MSA and $\mathrm{H}_{2} \mathrm{SO}_{4}$, predominantly present in aerosol, their wall loss was calculated using the aerosol data assuming the first order decay as a function of the aerosol size (McMurry and Grosjean, 1985). Details of the auxiliary mechanism that includes the wall chemistry of $\mathrm{NO}_{\mathrm{y}}$ species were described by Jeffries et al. (2000).

The background gases in the chamber, such as methane $(1.8 \mathrm{ppm})$, formaldehyde ( $8 \mathrm{ppb})$ and acetaldehyde $(2 \mathrm{ppb})$, were included in the model simulation. Methane is ubiquitous with a constant concentration. The concentrations of formaldehyde and acetaldehyde in the chamber were 


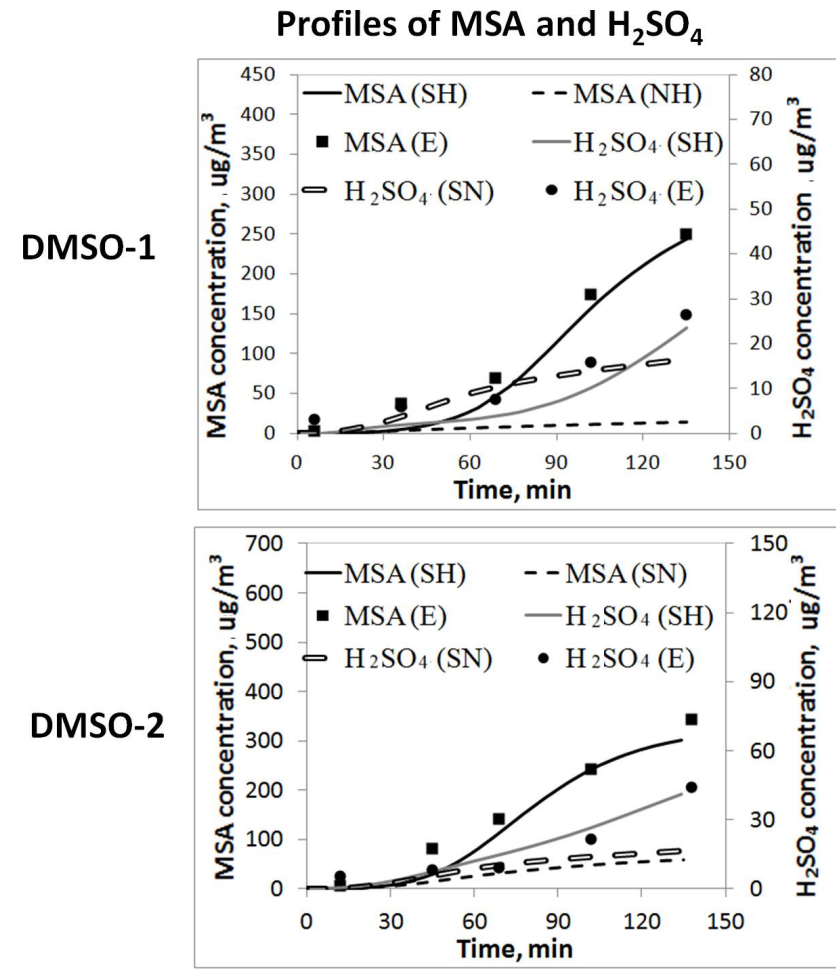

Fig. 2. Model simulation of $\mathrm{MSA}$ and $\mathrm{H}_{2} \mathrm{SO}_{4}$ for the photooxidation of DMSO in the presence of $\mathrm{NO}_{\mathrm{x}}$ (Exp DMSO-1 and DMSO-2 in Table 1) with (SH) and without ( $\mathrm{SN}$ ) including aerosol-phase reactions. The experimentally observed concentrations (E) of MSA and $\mathrm{H}_{2} \mathrm{SO}_{4}$ are shown as comparison. The production of MSA and $\mathrm{H}_{2} \mathrm{SO}_{4}$ was corrected for wall loss.

determined using GC-ITMS integrated with PFBHA derivatization.

\subsubsection{DMSO photooxidation}

Since the DMSO photooxidation mechanism is an important part of DMS photooxidation mechanism, before the evaluation of the DMS photooxidation model, the DMSO submodel was evaluated. Five DMSO photooxidation experiments (Exp DMSO-1, Exp DMSO-2, Exp DMSO-3, Exp DMSO-4 and Exp DMSO-5 in Table 1) were conducted to confirm the DMSO submodel. The model simulation of DMSO decay, the profiles of $\mathrm{DMSO}_{2}, \mathrm{SO}_{2}, \mathrm{NO}_{\mathrm{x}}$ and $\mathrm{O}_{3}$ agreed with observations (Exp DMSO-1 and Exp DMSO2 in Fig. 1). Without including the aerosol-phase reactions (Eq. R1-R9), MSA concentrations are significantly underestimated. As an example, the simulations versus observation (Exp DMSO-1 and Exp DMSO-2) before and after including the aerosol-phase reactions are shown in Fig. 2. Figures $\mathrm{S} 2$ and $\mathrm{S} 3$ summarize the corresponding information for Exp DMSO-3, Exp DMSO-4 and Exp DMSO-5 in Table 1. The profiles of $\mathrm{NO}_{\mathrm{x}}, \mathrm{O}_{3}$ and $\mathrm{SO}_{2}$ were not influenced by the aerosol-phase reactions.

\subsubsection{DMS photooxidation}

The DMSO submodel that contains aerosol-phase reactions of DMS products is included in the DMS oxidation mechanism. The new DMS chemistry scheme was simulated against five DMS photooxidation experiments. In the model of this study, the reaction of DMS with the $\mathrm{CH}_{3} \mathrm{~S}$. radical, the decomposition of the $\mathrm{CH}_{3}-\mathrm{SO}_{3}$. radical and the reaction of the $\mathrm{CH}_{3}(\mathrm{O}) \mathrm{S}(\mathrm{O})$. radical with $\mathrm{NO}_{2}$ were also included. These reactions have been either missed or assigned with improper estimates of reaction rate constants in the existing models (Yin et al., 1990a). The prediction of DMS decay and DMS product formation are improved after modification of the reactions.

Barnes et al. (1988) proposed the DMS $+\mathrm{CH}_{3} \mathrm{~S}$ - reaction in order to explain the fast decay of DMS in the presence of $\mathrm{NO}_{\mathrm{x}}$. It was found that, without this reaction, the model simulation of DMS decay is systematically slower than observation. The DMS $+\mathrm{CH}_{3} \mathrm{~S}$. reaction (Reaction No. 103 in Table S2) was thus added to the model with an estimated rate constant so that the decay of DMS and the profiles of $\mathrm{NO}_{\mathrm{x}}$ and $\mathrm{O}_{3}$ of the simulation result could be best fitted to that of observation in our study.

The reported reaction rate constant of the decomposition of the $\mathrm{CH}_{3}-\mathrm{SO}_{3}$. radical (reaction No. 46 in Table S1) spans between 0.004 and $51 \mathrm{~s}^{-1}$ (Campolongo et al., 1999). It was previously estimated to be $0.16 \mathrm{~s}^{-1}$ without experimental confirmation (Yin et al., 1990a). In this study, it was found that the change of this rate constant does not significantly influence the DMS decay or the $\mathrm{NO}_{\mathrm{x}}$ profile; rather, it impacts the distribution of $\mathrm{H}_{2} \mathrm{SO}_{4}$ and MSA. A value of $0.04 \mathrm{~s}^{-1}$ was found to best fit the measured concentrations of aerosolphase $\mathrm{H}_{2} \mathrm{SO}_{4}$ and MSA.

The rate constant of the reaction between the $\mathrm{CH}_{3}(\mathrm{O}) \mathrm{S}(\mathrm{O})$. radical and $\mathrm{NO}_{2}$ (reaction No. 24 in Table S1) was reported to be $(2.2 \pm 1.1) \times 10^{-12} \mathrm{~cm}^{3}$ molecule ${ }^{-1} \mathrm{~s}^{-1}$ (Ray et al., 2010) with one standard deviation of error. In this study, a value of $5 \times 10^{-13}$ (within two standard deviation of error of Ray's data) was found to best fit the $\mathrm{SO}_{2}$ and acid formation profile.

The major gaseous products of DMS oxidation were simulated and are shown in Fig. 3a (for Exp DMS-3, Exp DMS4 and Exp DMS-5) and Fig. S4 (for Exp DMS-1 and Exp DMS-2). In general, $\mathrm{SO}_{2}$ and $\mathrm{DMSO}_{2}$ were reasonably predicted. The measured DMSO concentrations in the experiments containing DMS were not reported in this study (see "Artifacts of DMSO measurement in the presence of DMS" section in the Supplement).

For aerosol-phase products, the model underestimated the concentrations of MSA and $\mathrm{H}_{2} \mathrm{SO}_{4}$ by up to a factor of three during the first $60 \mathrm{~min}$ of chamber experiments, but followed the measurements more closely during the rest of the experiments (Figs. 3c and S4c). In the model, aerosolphase reactions associated with DMSO, MSIA, and $\mathrm{DMSO}_{2}$ are controlled by partitioning processes that are governed mainly by the aerosol mass. However, in the early stage of 
(A) Profiles of DMS, $\mathrm{DMSO}_{2}$ and $\mathrm{SO}_{2}$

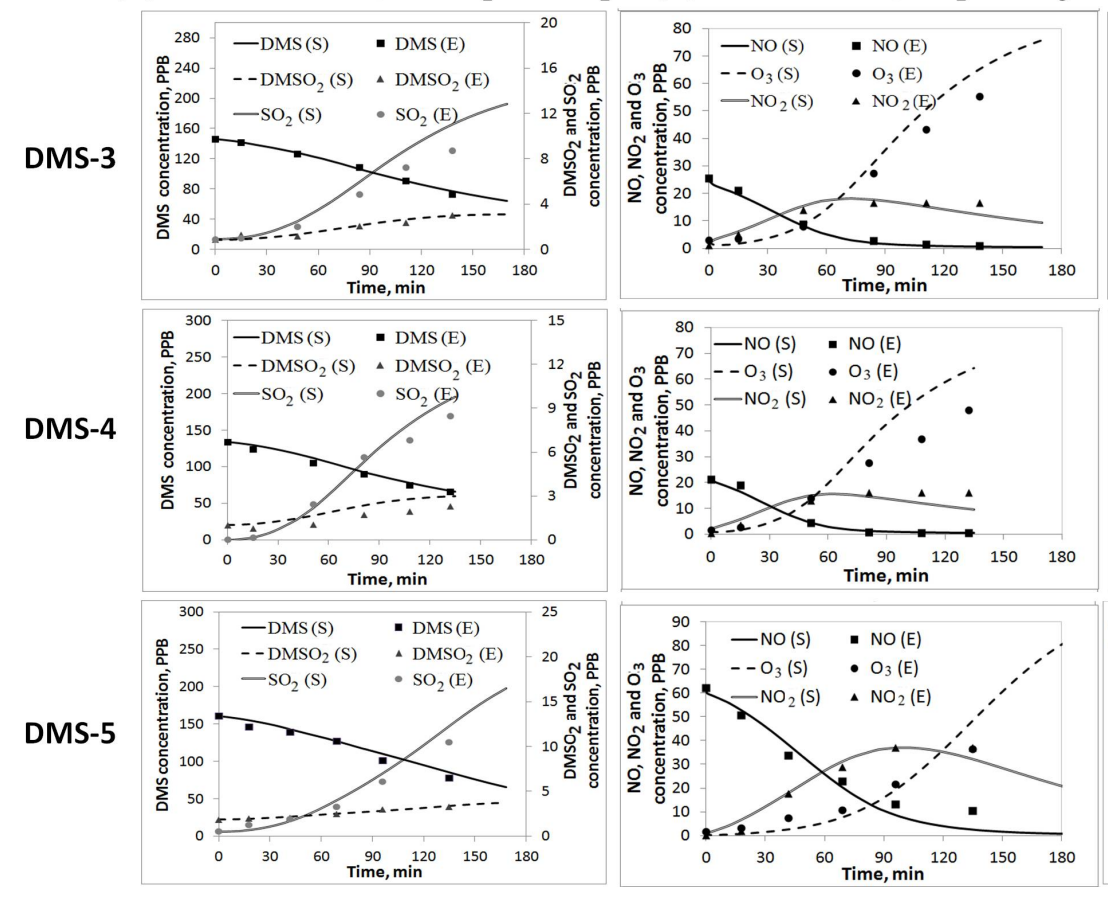

(C) Profiles of MSA and $\mathrm{H}_{2} \mathrm{SO}_{4}$
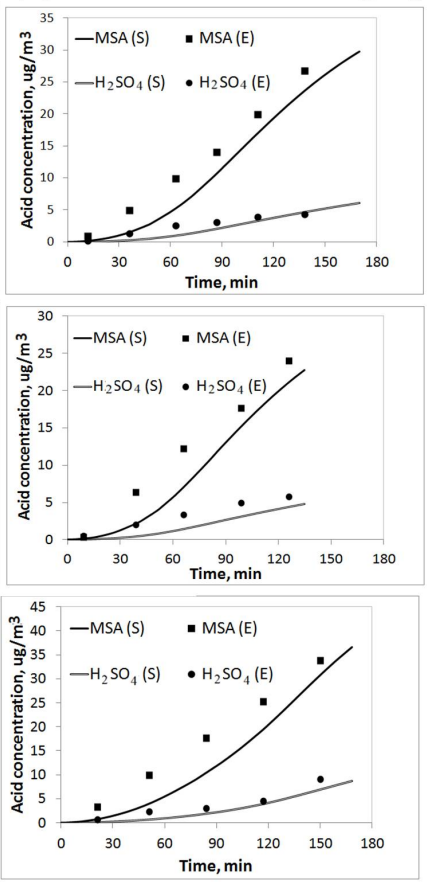

Fig. 3. Time profiles of DMS, $\mathrm{DMSO}_{2}, \mathrm{SO}_{2}, \mathrm{MSA}, \mathrm{H}_{2} \mathrm{SO}_{4}, \mathrm{NO}_{\mathrm{x}}$ and $\mathrm{O}_{3}$ for the photooxidation of DMSO in the presence of $\mathrm{NO}_{\mathrm{x}}($ Exp DMS-3, Exp DMS-4 and Exp DMS-5 in Table 1). "E" denotes the experimentally observed concentrations of chemical species and "S" for those simulated using the kinetic model.

the experiment, aerosols are small because they are formed via nucleation, so their surface area would be much more important than their mass in the partitioning processes. The model's predictions limit the accommodation of DMSO, MSIA, and $\mathrm{DMSO}_{2}$ due to the mass-based partitioning processes in the model. Consequently, the production of MSA and $\mathrm{H}_{2} \mathrm{SO}_{4}$ in the early stage of the chamber experiments was underpredicted in the model of this study.

\subsection{Impact of the coexisting isoprene on DMS photooxidation}

\subsubsection{Isoprene photooxidation}

The MCM v3.2 includes comprehensive isoprene photooxidation mechanisms including some very recently proposed mechanisms such as epoxide formation (Paulot et al., 2009). The isoprene model was simulated against Exp iso-1 and Exp iso-2. The major products ( $\mathrm{P} 1-\mathrm{P} 4)$ originating from isoprene were also simulated and compared to experimentally measured concentrations. The mass spectra data for isoprene's major gaseous products are summarized in Fig. S6 and the simulation results are plotted against observation in Fig. S6. Overall, the MCM mechanism predicts the isoprene decay, the formation of several isoprene products and the profiles of $\mathrm{NO}_{\mathrm{x}}$ and $\mathrm{O}_{3}$ well.

\subsubsection{DMS photooxidation in the presence of isoprene}

Experiments iso-DMS-1, iso-DMS-2 and iso-DMS-3 were carried out under similar initial concentrations of DMS and $\mathrm{NO}_{\mathrm{x}}$. The simulation profiles of DMS, isoprene, MSA and $\mathrm{H}_{2} \mathrm{SO}_{4}$ are shown in Fig. 4 in comparison with the measurements. The concentrations of $\mathrm{NO}_{\mathrm{x}}, \mathrm{O}_{3}$ and the gas phase products $(\mathrm{P} 1-\mathrm{P} 4)$ originating from isoprene oxidation are well predicted using the kinetic model (Fig. S7).

To understand the impact of isoprene on the production of MSA and $\mathrm{H}_{2} \mathrm{SO}_{4}$, molar yields (defined as the amount of a produced product divided by the amount of the consumed DMS) of MSA and $\mathrm{H}_{2} \mathrm{SO}_{4}$ were compared between experiments with different initial isoprene concentrations with similar amounts of DMS consumption. The yields of MSA and $\mathrm{H}_{2} \mathrm{SO}_{4}$ (in Table 3) were found to increase as the initial isoprene increases for both the model simulation and experimental data (after correction for wall loss and chamber dilution).

To understand the impact of isoprene on yields of MSA and $\mathrm{H}_{2} \mathrm{SO}_{4}$, the contribution of gas-phase reactions and aerosol-phase chemistry of DMS photooxidation to the formation of MSA and $\mathrm{H}_{2} \mathrm{SO}_{4}$ were analyzed using the integrated reaction rate (IRR) as shown in Table 3. The integrated reaction rate, expressed as an accumulated flux of chemical formation or consumption at a given reaction and an initial concentration, is estimated using the Morpho chemical 
(A) Profiles of DMS and isoprene
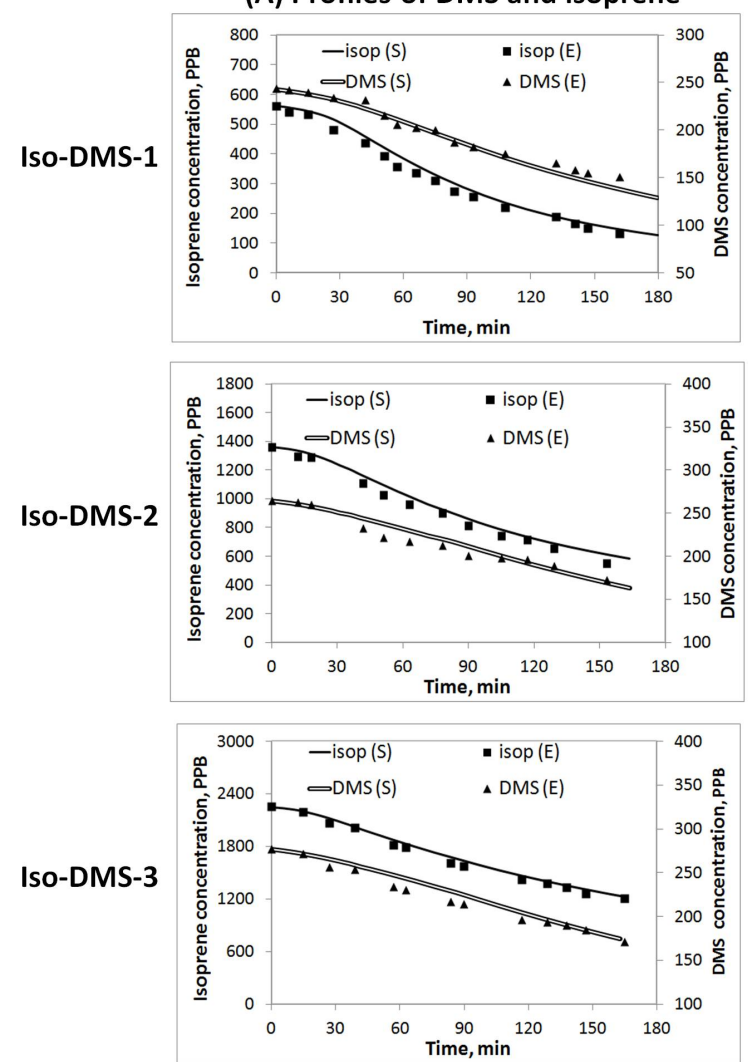

(B) Profiles of MSA and $\mathrm{H}_{2} \mathrm{SO}_{4}$
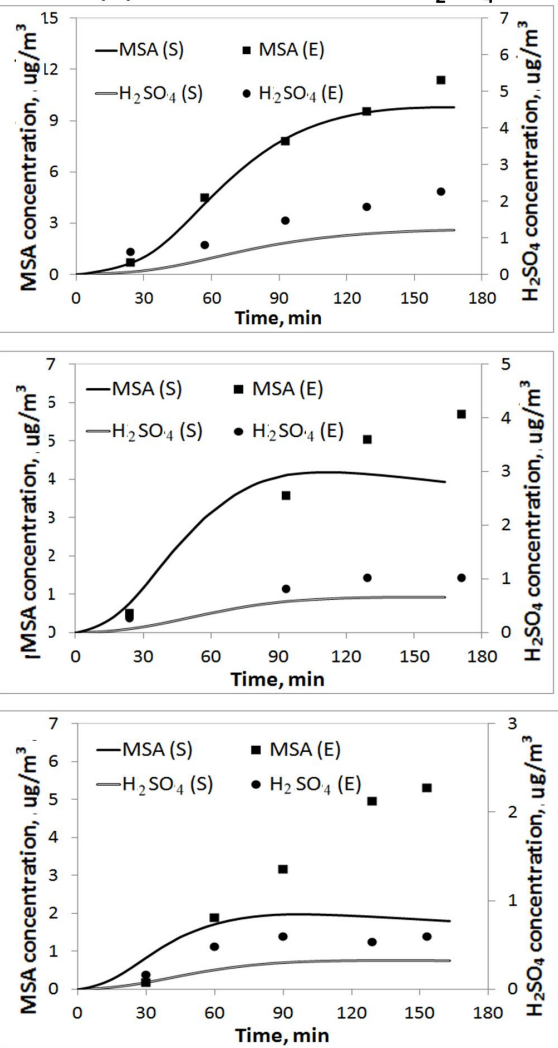

Fig. 4. Time profiles of isoprene, DMS, MSA and $\mathrm{H}_{2} \mathrm{SO}_{4}$ for the photooxidation of DMS and $\mathrm{NO}_{\mathrm{x}}$ in the presence of $560 \mathrm{ppb}$ (Exp isoDMS-1), $1360 \mathrm{ppb}$ (Exp iso-DMS-2), and $2248 \mathrm{ppb}$ (Exp iso-DMS-3) of isoprene. "E" denotes the experimentally observed concentrations of chemical species and "S" for those simulated using the kinetic model. The decay of DMS and isoprene was not corrected for the wall loss and chamber dilution while the production of MSA and $\mathrm{H}_{2} \mathrm{SO}_{4}$ was corrected for wall loss.

solver. Overall, the IRR values of the formation of both MSA and $\mathrm{H}_{2} \mathrm{SO}_{4}$ increase with the increasing initial isoprene concentration.

The IRR analysis suggests that higher initial isoprene concentrations enhance the formation of $\mathrm{SO}_{2}$, consequently increasing the production of $\mathrm{H}_{2} \mathrm{SO}_{4}$. The IRR (Table S5) of DMS with $\mathrm{O}\left({ }^{3} \mathrm{P}\right)$ was found to be the major variant among the experiments with different levels of isoprene concentration. The coexisting isoprene efficiently increases $\mathrm{NO}_{\mathrm{x}} \mathrm{cy}-$ cles during DMS photooxidation and also increases the reaction of DMS with $\mathrm{O}\left({ }^{3} \mathrm{P}\right)$ (Reaction No. 61 in Table S2), producing a $\mathrm{CH}_{3}$-SO radical with a unity yield. The resulting $\mathrm{CH}_{3}$-SO is efficiently oxidized into a $\mathrm{CH}_{3}(\mathrm{O}) \mathrm{S}(\mathrm{O})$. radical that is known to be a critical intermediate for the formation of $\mathrm{SO}_{2}$ and MSA (Yin et al., 1990a).

The effect of isoprene on MSA production is complicated because isoprene influences both gas-phase reactions and aerosol-phase reactions. Similarly to $\mathrm{H}_{2} \mathrm{SO}_{4}$, MSA formation in the gas phase is increased with higher isoprene concentrations due to the higher production of the $\mathrm{CH}_{3}(\mathrm{O}) \mathrm{S}(\mathrm{O})$. radical. MSA and $\mathrm{H}_{2} \mathrm{SO}_{4}$ produced through the gas phase mechanisms provide additional aerosol mass and conse- quently increase the MSA formation in the aerosol phase through the aerosol-phase reactions of DMS oxidation products.

Although the newly built DMS kinetic model of this study successfully predicts the trend (Table 3 ) in the yields of MSA and $\mathrm{H}_{2} \mathrm{SO}_{4}$ under different initial isoprene concentrations, the model's predictions somewhat deviate from experimental data when the isoprene concentration is high. Similarly, for Exp iso-DMS-1, Exp iso-DMS-2 and Exp iso-DMS-3 in Fig. 4, the model underpredicts MSA concentrations. The gap between measurement and prediction increases as the initial isoprene concentration increases. It is expected that the secondary organic aerosol (SOA) formed from isoprene photooxidation would influence the formation of MSA, possibly because the SOA might increase the solubility of DMS products such as DMSO. The aerosol-phase chemistry on isoprene SOA is not included in this study and this may possibly lead to the deviation of the model's predictions from experimental data. 
(A) Profiles of DMS and isoprene

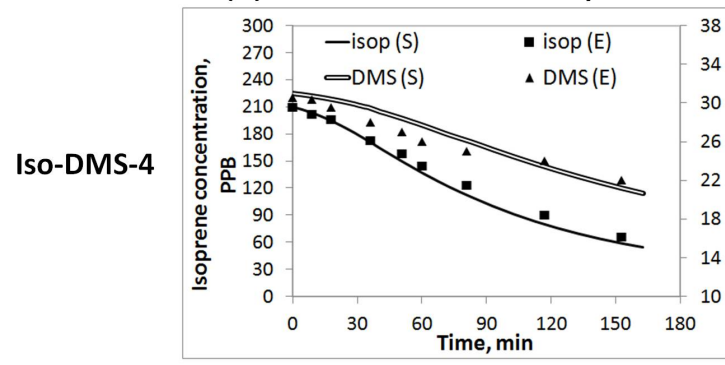

(A) Profiles of MSA and $\mathrm{H}_{2} \mathrm{SO}_{4}$

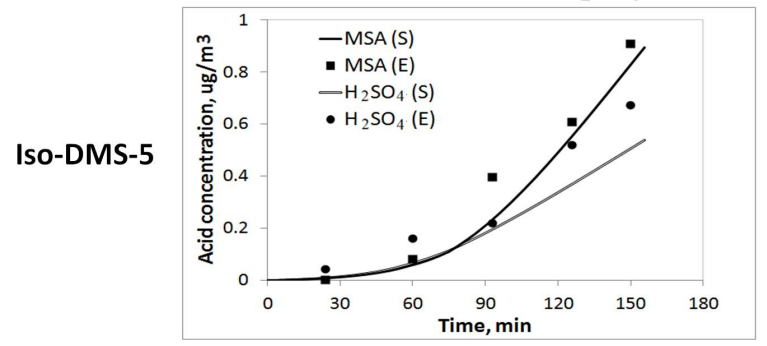

(B) Profiles of $\mathrm{NO}, \mathrm{NO}_{2}$ and $\mathrm{O}_{3}$

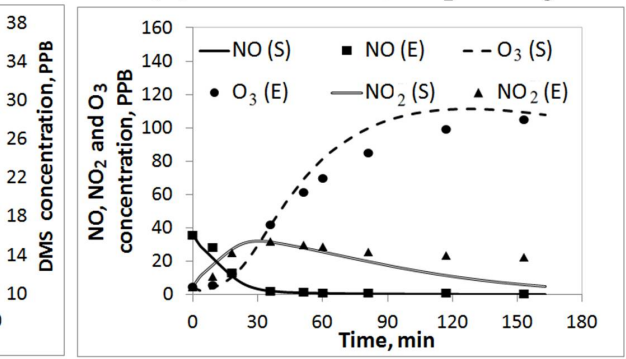

(B) Profiles of $\mathrm{NO}, \mathrm{NO}_{2}$ and $\mathrm{O}_{3}$

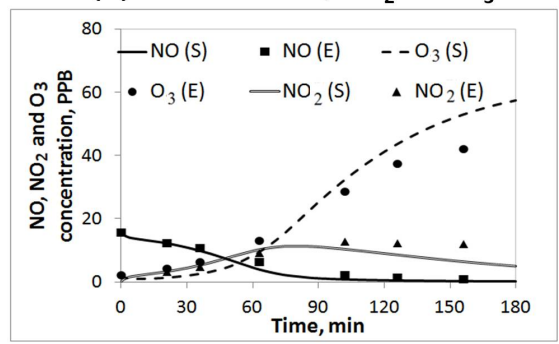

Fig. 5. Time profiles of Exp iso-DMS-4 (isoprene, DMS, $\mathrm{NO}_{\mathrm{x}}$ and $\mathrm{O}_{3}$ from the photooxidation of $31 \mathrm{ppb}$ of $\mathrm{DMS}$ and $40 \mathrm{ppb}$ of $\mathrm{NO}$ in the presence of $210 \mathrm{ppb}$ of isoprene) and time profiles for Exp iso-DMS-5 $\left(\mathrm{NO}_{\mathrm{x}}, \mathrm{O}_{3}, \mathrm{MSA}\right.$ and $\mathrm{H}_{2} \mathrm{SO}_{4}$ from $20 \mathrm{ppb}$ of DMS and $15 \mathrm{ppb}$ of $\mathrm{NO}_{\mathrm{x}}$ in the presence of $40 \mathrm{ppb}$ of isoprene). "E" denotes the experimentally observed concentrations of chemical species and " $\mathrm{S}$ " for those simulated using the kinetic model. The decay of DMS and isoprene was not corrected for the wall loss and chamber dilution while the production of MSA and $\mathrm{H}_{2} \mathrm{SO}_{4}$ was corrected for wall loss.

\subsection{Potential application of the kinetic model in ambient simulation}

To evaluate the model's performance for lower concentrations of isoprene and DMS, Exp iso-DMS-4 (isoprene: $210 \mathrm{ppb}$, DMS: $31 \mathrm{ppb}$ ) and Exp iso-DMS-5 (isoprene: $40 \mathrm{ppb}$, DMS: $20 \mathrm{ppb}$ ) were conducted. The simulation agrees well with measurements (Fig. 5) for both gas-phase and aerosol-phase products. Due to the detection limits of instruments, chamber experiments relevant to ambient concentrations of isoprene and DMS cannot be conducted in this study but simulated using the kinetic model. The simulation of the photooxidation of lower concentrations of isoprene and DMS is beneficial to evaluate the effect of both $\mathrm{NO}_{\mathrm{x}}$ and isoprene on the yields of MSA and $\mathrm{H}_{2} \mathrm{SO}_{4}$ and to understand the role of the aerosol-phase reactions of DMS oxidation products in the prediction of the production of MSA and $\mathrm{H}_{2} \mathrm{SO}_{4}$.

Figure $\mathrm{S} 8$ shows that higher $\mathrm{NO}_{\mathrm{x}}$ concentration increases the yields of both MSA and $\mathrm{H}_{2} \mathrm{SO}_{4}$ for $0.5 \mathrm{ppb}$ of initial DMS, which has been discussed by Yin et al. (1990b). Another conclusion from Figure S8 is that in the low concentration experiment, the yield of $\mathrm{H}_{2} \mathrm{SO}_{4}$ is higher than that of MSA. This is because the decomposition of $\mathrm{CH}_{3}-\mathrm{SO}_{3}$. (reaction No. 46) that produces $\mathrm{SO}_{3}$ becomes significant compared with its reaction with other oxidants that produces MSA.
Figure S9 illustrates the impact of the isoprene concentration on the yields of MSA and $\mathrm{H}_{2} \mathrm{SO}_{4}$ in the presence of $0.5 \mathrm{ppb}$ of initial DMS. In the early stage, isoprene has a similar impact on the yields of MSA and $\mathrm{H}_{2} \mathrm{SO}_{4}$ as observed in high concentration experiments. As reactions progress, the yields of MSA and $\mathrm{H}_{2} \mathrm{SO}_{4}$ tend to decrease with the increase of initial isoprene concentration. Because isoprene competes with its oxidation products for atmospheric oxidants such as $\mathrm{OH}$ and $\mathrm{NO}_{3}$ radicals, the reactions of $\mathrm{CH}_{3}(\mathrm{O}) \mathrm{S}(\mathrm{O})$. with atmsoperhic oxidants become less important and the decomposition of $\mathrm{CH}_{3}(\mathrm{O}) \mathrm{S}(\mathrm{O})$. (reaction No. 27) to $\mathrm{SO}_{2}$ is more important. $\mathrm{SO}_{2}$ yield has been confirmed through the model simulation showing significant increases with increasing isoprene concentrations. Since the reactions of $\mathrm{CH}_{3}(\mathrm{O}) \mathrm{S}(\mathrm{O})$. with atmospheric oxidants are the main sources of MSA and $\mathrm{H}_{2} \mathrm{SO}_{4}$, the yields of both MSA and $\mathrm{H}_{2} \mathrm{SO}_{4}$ decreases in the later stage of experiments with the high concentration of isoprene.

The model simulation also shows that the inclusion of aerosol-phase reactions in the model does not change the prediction of MSA and $\mathrm{H}_{2} \mathrm{SO}_{4}$ for the low concentration experiments. A possible reason is that the aerosol-phase reactions require aerosol mass, but in the simulation the initial aerosol mass is zero which makes the aerosol-phase reactions very slow. In the ambient aerosol, there is preexisting aerosols that can facilitate the aerosol-phase reactions of the semivolatile products from DMS photooxidation. In order to test the importance of the aerosol-phase reactions in the prediction of 
acid formation, a $4 \mu \mathrm{g} \mathrm{m}^{-3}$ of initial seed was included in the model. The simulation with and without the presence of initial seeds is shown in Fig. S10. The MSA concentration in the presence of initial seeds increases by $20 \%-50 \%$ compared to that without initial seed within 4-hour simulation. We conclude that the newly constructed DMS kinetic model can improve the prediction of MSA in the ambient air.

\section{Conclusion and atmospheric implication}

In this study, the modeling of DMS oxidation mechanisms has been advanced by including both the most recent reaction rate constants and aerosol-phase reactions of gas-phase DMS oxidation products in the aerosol. The newly constructed kinetic model closely matches the experimental data for the DMS decay and time profiles of $\mathrm{NO}_{\mathrm{x}}, \mathrm{O}_{3}, \mathrm{SO}_{2}$ and $\mathrm{DMSO}_{2}$. The prediction of $\mathrm{H}_{2} \mathrm{SO}_{4}$ and MSA concentrations has been significantly improved by the model of this study as compared with models that neglect aerosol-phase reactions of gaseous DMS oxidation products.

The MSA production appears to increase in the presence of isoprene. The IRR analysis in the model suggests that the presence of isoprene increases $\mathrm{NO}_{\mathrm{x}}$ cycles during the DMS photooxidation. Subsequently, the reaction of DMS with $\mathrm{O}\left({ }^{3} \mathrm{P}\right)$ is enhanced, eventually causing higher yields of MSA and $\mathrm{H}_{2} \mathrm{SO}_{4}$ through gas-phase reactions. With greater production of MSA and $\mathrm{H}_{2} \mathrm{SO}_{4}$ in the presence of high concentrations of isoprene, the aerosol-phase reactions of DMSO and MSIA were also enhanced, in turn producing more MSA. However, in the ambient relevant concentrations the model prediction suggests that isoprene may increase the yields of MSA and $\mathrm{H}_{2} \mathrm{SO}_{4}$ only in the beginning through the reaction of DMS with $\mathrm{O}\left({ }^{3} \mathrm{P}\right)$, but decrease them later. For very low concentration of DMS, the $\mathrm{CH}_{3}(\mathrm{O}) \mathrm{S}(\mathrm{O})$. radical produces $\mathrm{SO}_{2}$ instead of reacting with atmospheric oxidants and forming MSA and $\mathrm{H}_{2} \mathrm{SO}_{4}$.

Without aerosol-phase reactions, the gap between the observed MSA concentrations and the predicted concentrations become larger as the MSA concentration increases, as shown in DMSO-1 in Fig. 2 and DMSO-5 in Fig. S3. This tendency evinces that the production of MSA depends on the available aerosol mass, which directly influences aerosol-phase chemistry of both DMSO and its oxidation products such as $\mathrm{DMSO}_{2}$ and MSIA. The underprediction of both MSA and $\mathrm{H}_{2} \mathrm{SO}_{4}$ is also observed in the DMS-isoprene system even with aerosol-phase chemistry in the kinetic model. The underprediction of MSA appears to be greater when isoprene concentrations are higher. Such deviation might be caused by the lack of aerosol-phase chemistry of DMS oxidation products on isoprene SOA, suggesting that gas-phase mechanisms alone cannot correctly predict the formation of MSA.

For the mixture of DMS and isoprene, isoprene SOA modifies the chemical and physical properties of DMS aerosol and therefore, influences aerosol-phase reactions of DMS ox- idation products. Meanwhile, the DMS acidic products such as MSA and $\mathrm{H}_{2} \mathrm{SO}_{4}$ are able to catalyze aerosol phase reactions of isoprene oxidation products increasing SOA production (Jang et al., 2002). To improve the DMS oxidation model, the synergetic interaction between DMS oxidation products and isoprene SOA should be discovered in the future. In addition to the SOA issue, Zhu et al. (2006) indicated that the $\mathrm{OH}$. radical reaction with MSA consumes almost $20 \%$ of MSA and produces about $8 \%$ of $\mathrm{H}_{2} \mathrm{SO}_{4}$ within 3 days under typical marine atmospheric conditions. In this study, due to the short duration ( $\sim 3$ hours), the MSA decay might be insignificant. However, this should be considered when the model is applied to the reactions in the ambient air. Similar to the MSA production through aerosol-phase reactions of DMSO, $\mathrm{SO}_{2}$ can be oxidized in aerosol phase but will not be significant because of its low reactivity with oxidants (e.g., $\mathrm{OH}$ radical). However, in the ambient air, the aerosol-phase production of $\mathrm{H}_{2} \mathrm{SO}_{4}$ through $\mathrm{SO}_{2}$ reactions on aerosol should be considerable especially in the presence of atmospheric catalysts such as iron ions (Freiberg, 1974).

\section{Supplementary material related to this article is available online at: http://www.atmos-chem-phys.net/12/ 10257/2012/acp-12-10257-2012-supplement.pdf.}

Acknowledgements. This work was supported by grants from the National Science Foundation (ATM-0852747) and the Alumni Scholarship from the University of Florida. Publication of this article was funded in part by the University of Florida Open-Access Publishing Fund.

Edited by: D. Knopf

\section{References}

Atkinson, R., Baulch, D. L., Cox, R. A., Hampson, R. F., Kerr, J. A., and Troe, J.: Evaluated Kinetic and Photochemical Data for Atmospheric Chemistry. 3. Iupac Subcommittee on Gas Kinetic Data Evaluation for Atmospheric Chemistry, J. Phys. Chem. Ref. Data., 18, 881-1097, 1989.

Atkinson, R., Baulch, D. L., Cox, R. A., Hampson, R. F., Kerr, J. A., Rossi, M. J., and Troe, J.: Evaluated kinetic and photochemical data for atmospheric chemistry: Supplement VI - IUPAC subcommittee on gas kinetic data evaluation for atmospheric chemistry, J. Phys. Chem. Ref. Data, 26, 1329-1499, 1997.

Balla, R. J. and Heicklen, J.: Oxidation of Sulfur Compounds.2.Thermal Reactions of $\mathrm{NO}_{2}$ with Aliphatic SulfurCompounds, J. Phys. Chem.-US, 88, 6314-6317, 1984.

Ballesteros, B., Jensen, N. R., and Hjorth, J.: FT-IR study of the kinetics and products of the reactions of dimethylsulphide, dimethylsulphoxide and dimethylsulphone with $\mathrm{Br}$ and $\mathrm{BrO}, \mathrm{J}$. Atmos. Chem., 43, 135-150, 2002. 
Bardouki, H., da Rosa, M. B., Mihalopoulos, N., Palm, W. U., and Zetzsch, C.: Kinetics and mechanism of the oxidation of dimethylsulfoxide (DMSO) and methanesulfinate $\left(\mathrm{MSI}^{-}\right.$) by $\mathrm{OH}$ radicals in aqueous medium, Atmos. Environ., 36, 46274634, 2002.

Bardouki, H., Berresheim, H., Vrekoussis, M., Sciare, J., Kouvarakis, G., Oikonomou, K., Schneider, J., and Mihalopoulos, N.: Gaseous (DMS, MSA, $\mathrm{SO}_{2}, \mathrm{H}_{2} \mathrm{SO}_{4}$ and DMSO) and particulate (sulfate and methanesulfonate) sulfur species over the northeastern coast of Crete,, J. Phys. Chem.-US, 3, 1871-1886, 2003.

Barnes, I., Bastian, V., and Becker, K. H.: Kinetics and Mechanisms of the Reaction of Oh Radicals with Dimethyl Sulfide, Int. J Chem. Kinet., 20, 415-431, 1988.

Barnes, I., Hjorth, J., and Mihalopoulos, N.: Dimethyl sulfide and dimethyl sulfoxide and their oxidation in the atmosphere, Chem. Rev., 106, 940-975, 2006.

Barone, S. B., Turnipseed, A. A., and Ravishankara, A. R.: Role of adducts in the atmospheric oxidation of dimethyl sulfide, Faraday Discuss., 100, 39-54, 1995.

Campolongo, F., Saltelli, A., Jensen, N. R., Wilson, J., and Hjorth, J.: The role of multiphase chemistry in the oxidation of dimethylsulfide (DMS). A latitude dependent analysis., J. Atmos. Chem, 32, 327-356, 1999.

Cao, G.: Secondary organic aerosol formation from toluene oxidation in the presence of inorganic aerosols, Ph.D. dissertation, Department of Environmental Sciences and Engineering, 2008.

Charlson, R. J., Lovelock, J. E., Andreae, M. O., and Warren, S. G.: Oceanic Phytoplankton, Atmospheric Sulfur, Cloud Albedo and Climate, Nature, 326, 655-661, 1987.

Chen, G., Davis, D. D., Kasibhatla, P., Bandy, A. R., Thornton, D. C., Huebert, B. J., Clarke, A. D., and Blomquist, B. W.: A study of DMS oxidation in the tropics: Comparison of christmas island field observations of $\mathrm{DMS}, \mathrm{SO}_{2}$, and DMSO with model simulations, J. Atmos. Chem., 37, 137-160, 2000.

Chen, T. and Jang, M.: Secondary organic aerosol formation from photooxidation of a mixture of dimethyl sulfide and isoprene, Atmos. Environ., 46, 271-278, 2012.

Czoschke, N., Jang, M., and Kamens, R.: Effect of acidic seed on biogenic secondary organic aerosol growth, Atmos. Environ., 37, 4287-4299, 2003.

Davis, D., Chen, G., Bandy, A., Thornton, D., Eisele, F., Mauldin, L., Tanner, D., Lenschow, D., Fuelberg, H., Huebert, B., Heath, J., Clarke, A., and Blake, D.: Dimethyl sulfide oxidation in the equatorial Pacific: Comparison of model simulations with field observations for DMS, $\mathrm{SO}_{2}, \mathrm{H}_{2} \mathrm{SO}_{4}(g), \mathrm{MSA}(g)$, MS, and NSS, J. Geophys. Res.-Atmos., 104, 5765-5784, 1999.

Edney, E., Kleindienst, T., Jaoui, M., Lewandowski, M., Offenberg, J., Wang, W., and Claeys, M.: Formation of 2-methyl tetrols and 2-methylglyceric acid in secondary organic aerosol from laboratory irradiated isoprene/ $\mathrm{NO}_{\mathrm{X}} / \mathrm{SO}_{2} /$ air mixtures and their detection in ambient $\mathrm{PM}_{2.5}$ samples collected in the eastern United States, Atmos. Environ., 39, 5281-5289, 2005.

Freiberg, J.: Effects of Relative Humidity and Temperature on IronCatalyzed Oxidation of $\mathrm{SO}_{2}$ in Atmospheric Aerosols, Environ. Sci. Technol., 8, 731-734, 1974.

Gaston, C. J., Pratt, K. A., Qin, X. Y., and Prather, K. A.: RealTime Detection and Mixing State of Methanesulfonate in Single Particles at an Inland Urban Location during a Phytoplankton Bloom, Environ. Sci. Technol., 44, 1566-1572, 2010.
Guenther, A., Karl, T., Harley, P., Wiedinmyer, C., Palmer, P. I., and Geron, C.: Estimates of global terrestrial isoprene emissions using MEGAN (Model of Emissions of Gases and Aerosols from Nature), Atmos. Chem. Phys., 6, 3181-3210, doi:10.5194/acp-63181-2006, 2006.

Im, Y., Jang, M., Delcomyn, C. A., Henley, M. V., and Hearn, J. D.: The effects of active chlorine on photooxidation of 2-methyl-2butene, Sci. Total. Environ., 409, 2652-2661, 2011.

Jang, M., Czoschke, N. M., Lee, S., and Kamens, R.: Heterogeneous atmospheric aerosol production by acid-catalyzed particle-phase reactions, Science, 298, 814-817, 2002.

Jeffries, H., Sexton, K., and Adelman, Z.: Auxiliary mechanisms (wall models)for UNC outdoor chamber, Proceedings of the Sixth U.S./Germany Workshop on Ozone/Fine Particle Science, Office of Research and Development: Washington, DC, 20460, EPA/600/R-00/076, 2000.

Jenkin, M., Saunders, S., and Pilling, M.: Protocol for the development of the Master Chemical Mechanism, MCM v3 (Part A): tropospheric degradation of non-aromatic volatile organic compounds, Atmos. Environ., 31, 81-104, 1997.

Kamens, R., Jang, M., Chien, C. J., and Leach, K.: Aerosol formation from the reaction of alpha-pinene and ozone using a gas phase kinetics aerosol partitioning model., Environ. Sci. Technol., 33, 1430-1438, 1999.

Karl, M., Gross, A., Leck, C., and Pirjola, L.: Intercomparison of dimethylsulfide oxidation mechanisms for the marine boundary layer: Gaseous and particulate sulfur constituents, J. Geophys. Res., 12, D15304, doi:10.1029/2006JD007914, 2007.

Koga, S. and Tanaka, H.: Numerical Study of the Oxidation Process of Dimethylsulfide in the Marine Atmosphere, J. Atmos. Chem., 17, 201-228, 1993.

Lucas, D. D. and Prinn, R. G.: Mechanistic studies of dimethylsulfide oxidation products using an observationally constrained model, J. Geophys. Res.-Atmos., 107, 1-26, 2002.

Lukacs, H., Gelencser, A., Hoffer, A., Kiss, G., Horvath, K., and Hartyani, Z.: Quantitative assessment of organosulfates in sizesegregated rural fine aerosol, Atmos. Chem. Phys., 9, 231-238, 2009 , http://www.atmos-chem-phys.net/9/231/2009/.

McMurry, P. H. and Grosjean, D.: Gas and Aerosol Wall Losses in Teflon Film Smog Chambers, Environ. Sci. Technol., 19, 1176$1182,1985$.

Mihalopoulos, N., Kerminen, V. M., Kanakidou, M., Berresheim, H., and Sciare, J.: Formation of particulate sulfur species (sulfate and methanesulfonate) during summer over the Eastern Mediterranean: A modelling approach, Atmos. Environ., 41, 6860-6871, 2007.

Palmer, P.: Quantifying global marine isoprene fluxes using MODIS chlorophyll observations, Geophys. Res. Lett., 32, L09805, doi:10.1029/2005GL022592, 2005.

Pankow, J.: An Absorption Model of Gas/Particle Partitioning of Organic Compounds in the Atmosphere, Atmos. Environ., 28, 185-188, 1994.

Paulot, F., Crounse, J., Kjaergaard, H., Kurten, A., St Clair, J., Seinfeld, J., and Wennberg, P.: Unexpected Epoxide Formation in the Gas-Phase Photooxidation of Isoprene, Science, 325, 730-733, 2009.

Qi, B., Chao, Y. T., and Chen, Z. M.: Mechanism and kinetics of the production of hydroxymethyl hydroperoxide in 
ethene/ozone/water gas-phase system, Sci. China Ser. B-Chem., 50, 425-431, 2007.

Ramanathan, V., Crutzen, P., Kiehl, J., and Rosenfeld, D.: Atmosphere - Aerosols, climate, and the hydrological cycle, Science, 294, 2119-2124, 2001.

Rattigan, O., Boniface, J., Swartz, E., and Davidovits, P.: Uptake of gas-phase $\mathrm{SO}_{2}$ in aqueous sulfuric acid: Oxidation by $\mathrm{H}_{2} \mathrm{O}_{2}, \mathrm{O}_{3}$, and HONO, J. Geophy. Res., 105, 29065-29078, 2000.

Ray, A., Vassalli, I., Laverdet, G., and LeBras, G.: Kinetics of the thermal decomposition of the $\mathrm{CH}_{3} \mathrm{SO}_{2}$ radical and its reaction with $\mathrm{NO}_{2}$ at 1 torr and $298 \mathrm{~K}$, J. Phys. Chem.-US, 107, 6640$6645,2010$.

Sander, S., Friedl, R., Golden, D., Kurylo, M., Moortgat, G., Wine, P., Ravishankara, A.R.and Kolb, C., Molina, M., and FinlaysonPitts, B. J. and Huie, R.: Chemical kinetics and photochemical data for use in atmospheric studies, Evaluation Number 15, JPL Publication, 06-2, 1-523, 2006.

Saunders, S., Jenkin, M., Derwent, R. G., and Pilling, M. J.: Protocol for the development of the Master Chemical Mechanism, MCM v3 (Part A): tropospheric degradation of non-aromatic volatile organic compounds, Atmos. Environ., 3, 161-180, 2003.

Shaw, S., Gantt, B., and Meskhidze, N.: Production and Emissions ofMarine Isoprene andMonoterpenes: A Review, Adv. Meteorol., 2010, 1-24, 2010.

Takeuchi, A., Yamamoto, S., Narai, R., Nishida, M., Yashiki, M., Sakui, N., and Namera, A.: Determination of dimethyl sulfoxide and dimethyl sulfone in urine by gas chromatography-mass spectrometry after preparation using 2,2-dimethoxypropane, Biomed. Chromatogr., 24, 465-471, 2010.
Turnipseed, A. and Ravishankara, A.: The atmospheric oxidation of dimethylsulfide: elementary steps in a complex mechanism, in : G. Restelli and G. Angeletti (eds), Dimethylsulfide:Oceans, Atmosphere and Climate, Kluwer Acad. Publ., Dordrecht, Norwell, Mass., 185-195, 1993.

Urbanski, S. P. and Wine, P. H.: Chemistry of gas phase organic sulfur-centred radicals, edited by: Alfassi, Z. B., John Wiley and Sons, 97-140, 1999.

Welz, O., Savee, J., Osborn, D., Vasu, S., Percival, C., Shallcross, D., and Taatjes, C.: Direct kinetic measurements of Criegee intermediate $\left(\mathrm{CH}_{2} \mathrm{OO}\right)$ formed by reaction of $\mathrm{CH}_{2} \mathrm{I}$ with $\mathrm{O}_{2}$, Science, 335, 204-207, 2012.

Yin, F. D., Grosjean, D., and Seinfeld, J. H.: Photooxidation of Dimethyl Sulfide and Dimethyl Disulfide .1. Mechanism Development, J. Atmos. Chem., 11, 309-364, 1990a.

Yin, F. D., Grosjean, D., and Seinfeld, J. H.: Photooxidation of Dimethyl Sulfide and Dimethyl Disulfide .2. Mechanism Evaluation, J. Atmos. Chem., 11, 365-399, 1990b.

Zhu, L., Nenes, A., Wine, P. H., and Nicovich, J. M.: Effects of aqueous organosulfur chemistry on particulate methanesulfonate to non-sea salt sulfate ratios in the marine atmosphere, J. Geophys. Res.-Atmos., 111, D05316, doi:10.1029/2005JD006326, 2006. 